- \& - (1994) The community psychiatric nurse in primary care: an economic analysis. In Community Psychlatric Nursing. Vol. II. C. Brooker, \& E. White, London: Chapman \& Hall.

WHrTe, E. (1991) The Thind Qutnquennial National Community Psychiatric Nursting Survey. Untversity of Manchester: Department of Nursing Monograph.

- \& RHEY, E. (1993) A Detalled Study of the Relationship between Teaching. Support and Role Modelling for Students in Clinical Areas within the Context of
Project 2000 Courses. Royal College of Nursing. Research Advisory Group Conference: University of Glasgow.

Kevin Gournay, Professor of Mental Health. Faculty of Social Science and Education, Middlesex University, Enfield, Middlesex EN3 4SF

\title{
The relationship between a community psychiatric rehabilitation feam and local GPs
}

\author{
Sandra Tough
}

\begin{abstract}
As menial health profestionals move increasingly towards providing community-based senvices, a good working relationship with general practitionors becomes central to patient care. This relationship depends on good llotson and communication as well as shared ooats. This study examines the relationship between a community poychiaticic rehablitiation toam (CPR) and GPs by means of a poetal questionncire to local pincipals in general proctice. Although the awareness of the service was less than optimum, clear indications were made of ways of improving communication. The EPs ovenwholningty supported the priortlles of the CPRT in the care of those with major mental lilness.
\end{abstract}

Over the past 30 years the role of the psychiatric hospital in the care of those with long-standing mental health problems has declined, to be replaced by systems of community care (Thornicroft \& Bebbington, 1989). This has not only involved establishing alternative residential facilities but has also required provision for a range of support needs for people with multiple disabilities and disadvantages.

As psychiatrists and psychiatric nurses move increasingly into the local community, they may find their roles and responsibilities overlapping with other community based professionals, in particular general practitioners (Kendrick et al, 1991). There is therefore a need for community based psychiatric services to ensure good liaison and communication with other professionals as well as the development of shared aims and understanding (Bennet, 1989). The clinical role of the GP in providing primary medical care for the long-term mentally 111 has been recognised (House of Commons Social Services Committee, 1985). They are the most consistent point of contact with the caring professions for people who frequently drift in and out of psychiatric care.

This paper examines the relationship between a community-based psychiatric rehabilitation team and local GPs. 
Table 2. Assessment by GPS of the importance of individual elements of senvice provided by CPRT. (Results as number of GPs agreeing with statement)

\begin{tabular}{|c|c|c|c|c|c|}
\hline & Escontial & Important & Useful & Not Important & No Rophy \\
\hline Broad-based asessment & 34 & 17 & 7 & 1 & 1 \\
\hline Increasing social contact and reducing isolation & 17 & 33 & 7 & 2 & 1 \\
\hline Monitoring compliance with medication & 17 & 32 & 10 & 0 & 1 \\
\hline $\begin{array}{l}\text { Practical help with self care sklls and increasing } \\
\text { independence }\end{array}$ & 14 & 33 & 12 & 0 & 1 \\
\hline Providing a named person for llaison and contact & 23 & 24 & 12 & 0 & 1 \\
\hline Support for familles and carers & 16 & 31 & 10 & 2 & 1 \\
\hline $\begin{array}{l}\text { Helping patients and families cope with symptoms } \\
\text { of psychiatric illness }\end{array}$ & 16 & 27 & 13 & 0 & 4 \\
\hline Regular review of mental state & 10 & 35 & 13 & 1 & 1 \\
\hline Administering depot injection to known patients & 18 & 23 & 14 & 2 & 3 \\
\hline Assessing need for supported accommodation & 8 & 29 & 21 & 0 & 2 \\
\hline Co-ordination of care under the care programme & 10 & 21 & 22 & 1 & 6 \\
\hline Advising on appropriate state benefits & 6 & 20 & 31 & 2 & 1 \\
\hline
\end{tabular}

mental health services or expressed general dissatisfaction with mental health services. The mental health resource most used by the GPs was the community psychiatric nursing team with $65 \%$ estimating they made referrals monthly or more frequently.

\section{Communication}

The question on communication started with a statement that the CPRT wished to improve communication and gave four suggestions of ways of doing this as well as a chance to offer other suggestions. A very clear order of preference emerged (see Table 1) with initial notification to the GP of the key-worker and regular summaries of progress being the most popular option. Informal contact was also seen as effective, but regular formal review meetings to be least effective. Although liaison sessions with an individual team member were not popular overall, a significant minority showed considerable enthusiasm for this approach. Other suggestions were limited but the ideas of patient-held notes with basic information and practice-based CPN/counsellor to assess and refer to spectalist mental health teams were put forward.

\section{Assessment of attitude of GPs to aims and work of CPRT}

Following discussion with the CPRT, 12 key factors were identified as central to the role of the CPRT in caring for the long-term mentally ill (see Table 2). GPs were asked to grade the importance of each factor in the care of their patients with long-standing mental illness. Overall, more than half of GPs who replied considered all of the factors (with the exception of advice on state benefits) to be not simply useful, but essential or important for their patients.

A broad-based assessment of mental state. social situation and support needs was recognised as the most important factor with 34 GPs (57\%) agreeing that this was essential. Factors such as increasing social contact and reducing isolation, practical help with self-care skdlls, and increasing independence were given priority, along with support to families and carers and helping families and patients cope with the symptoms of psychiatric illness.

Although importance was given also to more medical factors such as monitoring compliance with medication, regular review of the patient's mental state, and administration of depot medication these were not given priority over the above factors which recognise the social support needs of patients and their families.

Other more formal social work roles such as assessing the need for supported accommodation and advising on appropriate state benefits were still seen as important although given less emphasis. Co-ordination of care under the care programme approach 
(CPA) was seen as less than essential, although regarded by the CPRT as an important aspect of their work.

\section{Comment}

The CPRT is relatively new and still developing a 'track record' with GPs. The concept of referral to a multidisciplinary team rather than a specific person or department is also new in this context. Despite considerable efforts to inform GPs of the CPRT's existence and role, their awareness of the team was still lower than hoped for. This must in part be due to the small number of patients known to individual GPs who would benefit from the CPRT. In addition. GPs may see referrals to such specialist teams as essentially tertiary, preferring to send patients to the general psychiatrists or generic community psychiatric nurses for assessment. Indeed it may be argued that experienced mental health professionals are better placed to make appropriate referrals to a specialist team. A counter-argument is that a community based team is likely to be more effective if working closely with other professionals involved in an individual's care in the community. The ability of GPs and other professionals to refer directly to the team may improve this relationship. If direct referrals from GPs are to be encouraged, there is a need for repeated contact and good communications. Clearly GPs would appreciate more information on the CPRT's involvement with their patients. To date, feedback would only be given routinely to GPs if they were the referring agent. This needs to be reviewed and could be a simple and effective way of improving awareness and communication.

Formalised co-ordination of community care (such as under the CPA) emphasise improved communications and formal review meetings are a central part of this. GPs, in this study however, do not see this as a practical or desirable method of routine communication. Although liaison sessions with an individual team member may not be possible with every practice immediately, arranging this on a limited basis with practices who showed an interest might well be beneficial and give indicators for future service development.

It is reassuring that the priorities of the CPRT in their care of those with long-standing mental health problems are so strongly supported by GPs. In particular, the need for social, practical and family support, as well as the treatment and monitoring of illness are recognised by both as central, emphasising the need for a multidisciplinary, multi-skilled approach to rehabilitation of the mentally ill in the community.

The relatively low importance attached to the CPRT's role in co-ordination of care under the CPA is disappointing, in view of the emphasis given to the CPA by the government as a means of ensuring the provision of care in the community to the vulnerable mentally ill. However, at the time of the survey the CPA was relatively new and the GPs were perhaps not familiar with it. It would be interesting to see if their view changes with time.

\section{References}

Bennet, C. (1989) The Worcester Development Project: general practitioner satisfaction with a new community poychiatric service. Joumal of the Royal College of Ceneral Practitioners. S9. 106-109.

DEPARTAENT Of HEALTH (1990) The Care Programme Approach to People with Mental Illness Referred to the Specialist Psychiatric Services. (HC (90) 23/LASS (90) 11).

House of Commons SOCLL SERVICES Comantrere 1985 Communtty Care (2nd Report) London: HMSO.

Kendruck. T. Siband. B. et al (1991) Role of general practitioners in care of long term mentally ill. Brttish Medical Journal, S02, 508-510.

Thornicroft, G \& BEBBnGton, P. (1989) De institutionalisation-From hospital closure to service development. British Journal of Psychiatry. 186, 739 753.

Wrson, A. O. A. (1973) A resettlement Scheme in Northumberland and North Tyneside: towards integrated mental health service (ed. D.A. Stephens) Smith Kline \& French Publications.

Sandra Tough, Senior Registrar in Psychiatry, The Hadrian Clinic, Newcastle General Hospital, Westgate Road, Newcastle upon Tyne NE4 6BE 